\title{
Continued Visual Objectification: The Image of the Fair Sex in Occidental Advertisements
}

\author{
Noraini Md. Yusof \\ Center for Occidental Studies, Institute of Malaysian and International Studies (IKMAS), \\ National University of Malaysia (UKM) , 43600, Bangi, Selangor, Malaysia \\ Email: animy@ukm.edu.my \\ Esmaeil Zeiny Jelodar \\ Center for Occidental Studies, Institute of Malaysian and International Studies (IKMAS) \\ National University of Malaysia (UKM), 43600, Bangi, Selangor, Malaysia \\ Email: ezeiny@ukm.edu.my \\ Shahizah Ismail Hamdan \\ School of Language Studies and Linguistics, National University of Malaysia (UKM) \\ 43600, Bangi, Selangor, Malaysia \\ Email: sha@ukm.edu.my
}

\section{Doi:10.5901/mjss.2014.v5n20p2886}

\section{Abstract}

\begin{abstract}
Portrayals of women in the mass media have always been a source of contention amongst scholars. Right from the emergence of the mass media, women have been stereotypically portrayed as an inferior being whose primary domain was home and who was viewed as a sexual object. In spite of feminists' efforts to stop women's denigration in the media over the course of several decades, women are still depicted as weak and sexual object, especially in the advertising industry. The visual objectification of women engenders a distorted view of the place of women in society. This paper examines the images of women in Occidental advertisements and exhibits that the stereotypical objectification of women leads to desensitization of violence against women and causes women to develop self-objectification. To counter the effect of the images, we argue that media literacy can help people to critically look at the images and recognize the constructed fantasy from reality.
\end{abstract}

Keywords: Visual objectification, Women, The Fair Sex, Advertisement

\section{Introduction}

For several decades now, scholars have been focusing on the ways in which women are stereotypically portrayed in mass media. In fact, a large scholarship has quantified and qualified the mass media's guilt against women, especially since Tuchman (1978) introduced the concept of 'symbolic annihilation' to study sexism in the media. The term 'symbolic annihilation' refers to women's regular deletion, trivialization and stereotyping in the mass media (Tuchman, 1978). Since then, a number of feminist scholars such as Gough-Yates $(2003$, p. 7) argue that the mass media contribute to the "reinforcement of gender differences and inequalities." Despite all the feminists' struggle to stop the media from denigrating and misrepresenting women, the structures of female exploitation and subordination remained unchallenged. They still face many of the same problems that were evident and began some decades ago. There has been a disproportionate emphasis on women's traditional domestic roles and their being rendered as sex objects in occidental visual media including television, films, news, magazines and advertisements. This objectification/commodification of the fair sex in occidental media, especially advertisements leaves a great impact in societies. The visual objectification of the fair sex is not only used to sell products but it also impinges upon many girls and women of a society as women in advertisements are thought to be the ideal standard size and beauty of a woman. Resulted from the images, frustration and disappointment can be found amongst the female sect of the society as they see themselves far away from the (un)realistic standards of femininity portrayed in the media.

As an offshoot of media, advertisement is the most potent and rife tool that influences people to view gender. Being ubiquitous in people's daily lives, it insinuates messages into our consciousness at every turn. People are incessantly exposed to visual advertisements that stimulate them to purchase products or services. According to Kang 
(1997), these images of advertisements are also socializing agents that affect people's attitude, beliefs, values and behaviors. This description tallies with what Gallargher $(1979$, p. 3) thinks of media as "potentially powerful agents of socialization and social change - presenting models, conferring status, suggesting appropriate behaviors, [and] encouraging stereotypes." Therefore, as advertisements carry messages about gender in terms of standard appearance and appropriate behavior, they shape one's ideas of what it means to be a man or a woman in the society (Linder, 2004). This statement conjures up Goffman's (1979) idea on advertisement which argues that the portrayals of men and women in advertisements are oftentimes perceived to represent the whole nation; thereby people accept them as norms. Many of today's advertisements on women exhibit separate parts of a woman's body as "buttocks, thighs, legs, breasts, facial skin" (Carter \& Weaver, 2003, p. 122). These nude images are ready and primed to be emulated and at times fetishized (Caputi, 1999; Kilbourne, 1999). The regular reproduction of these mostly male constructed images finds its way into daily discourse and delicately defines the "contours and limits of the "proper" way of looking and being female" (Byerly \& Ross, 200, p. 37).

\section{Visual Objectification}

The media is fraught with objectification of women. For example, women in western cultures are being socialized to incorporate an external view of their physical self, one that objectifies them as sex object (Fredrick \& Roberts, 1997). Women in the media, especially in advertisements, are portrayed unrealistically thin and flawlessly beautiful. To sell their products, advertisers usually focus on portions of women's body rather than the entire body which signifies the view of the fair sex as an object (Anthony, 2009). The contribution of the objectification of the fair sex to advertisement can be corroborated by Duke \& Kreshel (1998, p. 49) when they put "dissected into physical parts- eyes, lips, breasts, legswomen are constantly made aware of chronic imperfections, then [the] offered products ... will help them attain the socially constructed ideal." The visual objectification of women in advertisements is so powerful to the extent that selfobjectification of women emerged in western societies. Fredrickson \& Roberts (1997) argue that self-objectification arises once a woman measures her body from a third person perspective with a focus on their discernable bodily features. It also occurs because advertisements sell images of sexuality, normalcy and popularity more than products. Therefore, it could be argued that these objectification images are successful in telling women who they are and who they should be (Kuntjara, 2001). Once taken as a piece of art, the success of a work of art is "often judged on the basis of its capacity to create in the mind of the viewer or reader a feeling of plausibility, if not outright believability" (Karl, 1994, p. 199).

The visual world of advertisements creates powerful images that produce an inescapable influence of 'believability.' According to the American Association of Advertising Agencies' report, people see up to 3,000 advertisements every day, which adds up to more than one million annually. Needless to say this amount of sheer exposure to advertisements has a boundless impact on people. As a part of our daily vision, we are so habituated to this world of images that we simply read images of what we see without much reflection. The visual objectification of the fair sex in advertisements leads to self-objectification because women believe in what they see. These consistent and regular images construct a particular depiction of (un)reality in women as they see more and more images of objectified women in the media. Studies exhibit that the objectification of the fair sex in advertising not only leads women to have an overall more negative self-body image but also it affects how we view women's roles in a society. It helps in desensitizing views of violence against women as well. Viewing these images can give birth to "devaluations of one's - and one's partner'sattractiveness, attitudes supportive of aggressiveness toward women, triggering of gender stereotyping and gender role expectations, and distorted body image" (Reichert, 2007, p. 82). The consequent distorted view is the main product of the symbolic annihilation of women in advertisements.

Objectification of the fair sex, as mentioned earlier, contributes to a climate in which gender stereotyped attitude is reinforced and exploitation of women and violence against them are both tolerated and subtly encouraged. Advertisement as a powerful medium usually connects sexuality and victimization together. Bessenoff (2006) notes that when women are presented as sex objects and victims in the media, people of a society become numb to this aggression against women. When they see a class of human beings treated as objects, or in ways that forcefully lower them to objects, it becomes an easier task for men to use women as an object with little regard. Studies show that sexual violence against women appears to be justified when men simply view women as objects and it "can increase men's acceptance of rape myths, interpersonal violence, and gender role stereotyping" (Stankiewicz, 2008, p. 587). It is apparent that the link of sexuality and victimization in advertising affects the male psyche by causing them to heedlessly become 'desensitized' to the synthesis of sex and violence (Buie, 2010). Desensitization to violence against women has become so common in western societies that one in four women have been victims of rape or attempted rape, and many college girls experienced some kind of sexual victimization (Fisher, Cullen \& Turner, 2000; White, Donat \& Bondurant, 2001). 
Stankiewicz (2008) further argues that the regular images of women as sex objects in media cause people to think that a woman's physique and sexuality are what makes her precious. In fact, objectification of the fair sex equates their worth with their body's appearance and sexual functions in people's view.

\section{Stereotyped/Gendered Advertisements}

People construct their knowledge of the world by arranging and simplifying the information they receive. They create cognitive schemes which are able to describe the substance of their perspectives and dramatically impact social cognition. Wolska (2011) believes that stereotypes are the most significant type of schemes which are used for orientation in the social environment. Stereotypes could be adopted and internalized from the influence of sources such as media. Media have always been communicating images of the sexes, and advertisement as a form of media is no exception. Images of unrealistic, stereotypical and limiting perceptions are recruited to represent gender. Women are usually underrepresented to suggest that the cultural standard has to be sought through images of men which imply that women as the fair sex of the society are invisible and insignificant (Wood, 1994). This underrepresentation reflects and fortifies the socially sanctioned perspectives of gender and normalizes violence against women. In Occidental media advertisements, women have always been portrayed either as a cleaning, cooking or child-bearing machine or as a sex object. These cliché images of women are then constructed and circulated to form feminine identities (Gough-Yates, 2003). That is how cultural constructions of inequality, domination and oppression came into existence. Van Zoonen (1995) notes that the representation of gender in media, both masculinity and femininity, are articulation of dominant gender discourse and echoes a bifurcated and binary definition of gender. Van Zoonen (1995, p. 320) further argues that the representation of women in the media are associated with terms such as "underrepresentation, family context, lowstatus jobs, no authority, no power, related to others, passive, emotional, dependent, submissive and indecisive" and not to mention as sex objects. Men are usually portrayed with images conveying overrepresentation, work context, highstatus jobs, authority, potent, active, individual, rational, independent and resolute (Van Zoonen, 1995). On these stereotypical male constructed images of women in advertisements, Felski (2000, p. 182) opines:

All...visions of women are contaminated by male-defined notions of the truth of femininity. This is true not only of the negative cultural images of women (prostitute, demon, medusa, bluestocking, vagina dentata) but also of positive ones (women as nature, women as nurturing mother, or innocent virgins, or heroic amazon...). Woman is always a metaphor, dense with sedimented meanings.

Exposure to these stereotyped portrayals influences gender stereotyped attitudes. Tuchman $(1978$, p. 30) is of the idea that the mass media including advertisements "disseminates the same theme about women to all social classes: They announce their symbolic annihilation and trivialization." Women in advertisements are framed negatively to promote the "patriarchal" form of "acceptable femininity" (Byerly \& Ross, 2006, p. 50). Images of women in advertisements are orchestrated to consolidate subordination of women. These male-constructed cultural stereotypes are strikingly different from reality as women have been dramatically underrepresented right from the emergence of mass media in the west. Prime-time television in 1987 aired programs with more men than women, two-thirds of the speaking parts were allocated to men (Wood, 1994). They were portrayed as significantly passive, dependent on men and entangled in relationship or housework (Davis, 1990). Women were always depicted as less outspoken than men. To bolster this stereotype of women subordination, a new talking Barbie doll was created in 1992 which said "Math class is tough;" this reiterated the stereotype that women cannot be successful in math and science (Mattel Offers Trade-in 1992). Advertising which perpetuates gender stereotypes suggests that servility oozes out of women. Women's image has been exploited in advertisements in "proportion to" their "exclusion form cultural participation" (Mulvey, 1979, p. 179). Women in advertisements are always busy with dirt and are housebound (Bardwick \& Schumann, 1976). Many women internalize this stereotype and think of themselves as inferior who should always be in the domestic domain.

The stereotypes of subordination are usually concomitant with portrayals of beautiful, young, thin, attractive and flawless women. As a form of mass media, advertising reiterates the cultural portrayals of women as dependent and beautiful decorative sex object whose primary functions are to look sexy, please men's lust, and stay as an obedient sex object. These young, flawless, beautiful and sexy images of women are portrayed ideally to sell everything from cigarettes to clothing to household items. Kilbourne (2000) argues that the near-naked women in advertisements who are perfectly portrayed represent only five percent of women; however, in the advertising industry this perfect body type represent $98 \%$ of women which lead women to think that this is the standard beauty and size. The constant message that these advertisements produce is that women are not good enough the way they are and they need the products and services being sold to enhance their physique and beauty. They are also shown as sexy to attract and attain a male. Sexism is reinforced in advertisements when women are shown in subordinate, subservient and male pleasing roles. 
These stereotypes penetrate into the popular culture of the west and influence the rank and file. They see the stereotypes and act accordingly because stereotypical portrayals are taken as a socially acceptable reality. Being repeatedly exposed to the heavily use of women as "sexualized product adornments" (Pritchard, 2001, p. 79), these stereotypical images crystalize into a form of perspective. On the influence of these bromidic images, Pritchard (2001, p. 91) believes that when:

female images are overwhelmingly restricted to these prescribed and subordinate roles, they serve not only to distort reality, but also, by maintaining sexist stereotypes, to constrain female identities. Such images play a vital role in creating and maintaining everyday perceptions of accepted roles for women and men - and if the majority of images are limiting or even degrading they significantly contribute towards legitimizing such images...

The daily exposures of people to these images produce cultivation effect. It is the "teaching of a common worldview, common roles and common values" through everyday exposure to the same images (Gerbner, Gross, Morgan \& Signorieli, 1980, p. 10). It is undeniable that images, especially media images have an extraordinary power that last in the mind. Living in a visually saturated culture, individual perception and rationality are overridden by the powerful and often persuasive images of advertisements. People register the stereotypical images without putting much thought into it and they are likely to perceive the world through what is portrayed in advertisements. They interpret the images based on their "accumulated cultural knowledge" as every discourse and every reading of it hinges on "prior codes" (Spencer, 2011, p. 19). Kristeva (1981) argues that "whatever the semantic content of a text, its condition as a signifying practice presupposes the existence of other discourses;" this means that right from the beginning every text is "under the jurisdiction of other discourses which imposes a universe on it" (Kristeva quoted in Culler, 1981, p. 116). Therefore, people read images before their eyes through the pictures they have in their heads (Spencer, 2011). The pictures in their heads are the 'accumulated cultural knowledge', one of which is the objectification of women. These stereotypical images of women in advertisements are collectively interpreted as undermining women and their abilities. The cultivation of these stereotypes suggests that internalization of these images happen without much deliberation and comprehension.

\section{The Body of the Fair Sex}

The depiction of women is one aspect of advertisements which is in need of change. Advertisers have been following three types of stereotypes in portraying women: they are weak, they are beautiful, and they are sex objects. A female body is used as a medium to convince an audience to buy services and products. Women and their body parts are used to promote and sell everything from cigarettes to drinks to body sprays and to men's clothes. Especially of interest are the debates about the presence of females in advertising. Wells, Burnett and Moriaty (1997) argue that females are used in advertising because they are responsible for most of the purchasing done for their homes. However, as the fair sex of the society, their bodies are sexualized to catch viewers' eyes. Whatever the debate, it is clear that they are the victim of popular culture in a male-dominated advertising industry. The male constructed images of women reinforce the stereotypes of women as an inferior being and sex objects. Marginalizing, subordination and commodification of females in advertisements are on the rise to the extent that one would think the industry is celebrating chauvinism. Domesticating the women was one of the early stereotypes reinforcing the idea that a woman should be a good housewife and a good mother. Women were, oftentimes, depicted in the home and happily engaging with the household chores (fig.1).

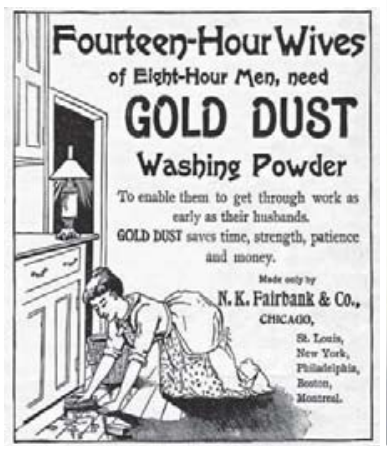

\section{Look Familiar?}
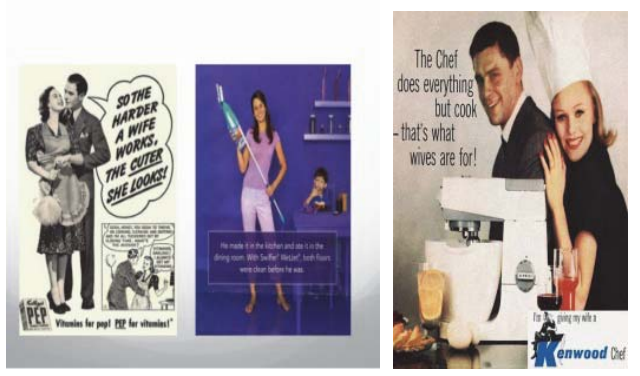

Fig.1. Advertisements depicting women as a housewife and a mother. 
In the above advertisements, domesticity of a woman is highlighted. The "happy housewife" stereotype had its own unique impact on women. Many women saw it as a cultural directive which led them to ignore their longing regarding career and personal life and substituted them with the "ideal" presented to them through advertising (Geis et al, 1984; McArthur \& Resko, 1975). Although this kind of stereotype is no longer in vogue as many women have adopted a modern lifestyle and work outside the home, it still exists in fewer numbers. It is true that there was a shift in portraying women from domesticity to the outside world and women are not solely depicted as the stereotypical "happy housewife" roles any more. However other delicate ways have been presented to portray women as inferior to men. Kang (1997, p. 994) argues that even though a great number of advertisers began to portray more powerful and self-reliant women, "only superficial cultural alterations are transferred to advertisements, while the underlying ideological foundation remains untouched." Women have never been depicted as powerful and controlled as men. When it comes to depict both men and women in an advertisement, women are usually the sexual objects of men. They are portrayed as either lying down or standing with covered faces and mouths (fig. 2). The advertisements usually depict men controlling women's bodies by "lifting them up, containing their space by encircling their bodies, by blocking access to the women's body, or by putting their arms around women's shoulders" (Linder, 2004, p. 412). In addition, women are more likely to be shown as holding onto men's arm or resting their weight on men's body (fig. 2).
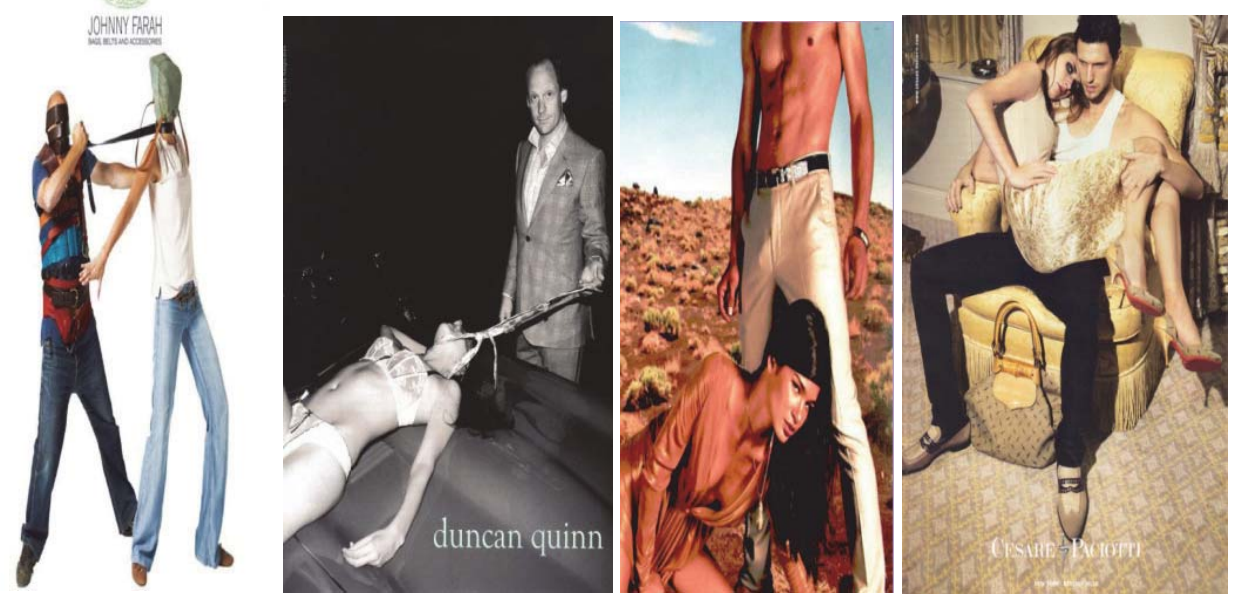

Fig.2. Advertisements depicting women's submissiveness.

All the above images signify vulnerability of women and their need for protection and being controlled. The first advertisement which features the brand of Johnny Farah portrays a man with several belts tied around his torso and head pulling a belt which is tied around the neck of the female. The woman's face is covered by a purse which insinuates that women should be uninvolved and withdrawn from the social participation. Although Johnny Farah is a Lebanese brand, the advertisement is widely circulated in the west. The second advertisement is promoting Duncan Quinn's products. It sells handmade ready-to-wear and bespoke men's suits. The woman is portrayed lying down on a car with the man's tie around her neck like a dog collar in the man's hand. The image is consolidating the stereotype of patriarchy. The same holds true for the other two advertisements which depict women as a submissive and dependent being. These images in advertising along with so many other images which depict women as an object of possession instill and consolidate men's power over women. Too often women are reduced to the sum of their body parts in advertisements which indicate the fact that men view women as an object (fig. 3). They are portrayed to be seen for a voyeuristic gaze and are commodified as sexual object. There are also many advertisements which are completely unrelated to sex but still feature objectification and demoralization of women; conflating women with food is one such advertisement (fig. 3). These images are indicative of the fact that patriarchy still exists although many may argue that patriarchy is nothing but history in western societies. Contrarily, in modern time, patriarchy and capitalism work in tandem to suppress women. According to Pierson (1986, p. 13) patriarchy has: survived the industrialization of western society under capitalism. Women as a group have remained subordinate to men as a group. To speak of the subordination of women and the superordination of men reflects the differing relation of women and men to power in the sense of "power over," of dominance. A power difference is part of the inequality of the male-female relationship under patriarchy: male dominance is the other side of 
women's subordination. The enforced economic dependence of many women on male providers has contributed greatly to the perpetuation of that power difference and the survival of patriarchy.
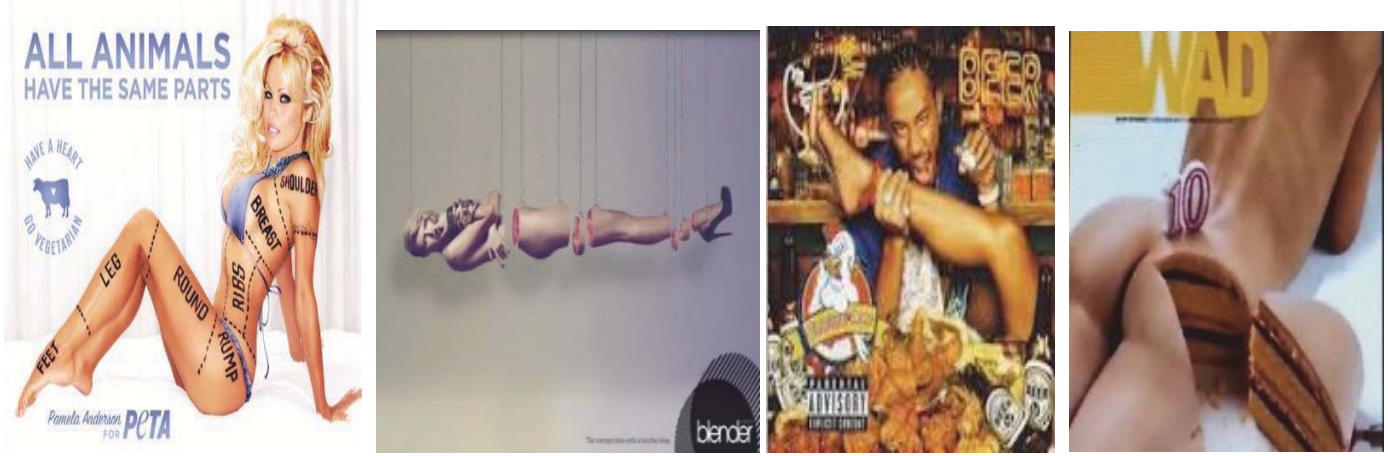

Fig.3. Advertisements depicting women as separated parts

What Pierson expressed almost three decades ago can be corroborated by Kilbourne (2000) when she states that the advertising industry is monopolized by male where women are degraded, stereotypes reinforced and objectification of women is encouraged. Therefore, patriarchy and capitalism feed off one another in forming women's gendered existence. In patriarchal societies men hold the primary power and under capitalism the means of production are monopolized by men. In either case, masculinity has the upper position where it normalizes male dominance and female subordination. As mentioned earlier, images have the power to influence and shape people's perception and attitude towards gender. Images in figure three are encouraging the objectification of women's bodies which could lead people to view women not as whole but as separate parts. The first image features Pamela Anderson advertising vegetarianism; her sexualized body is partitioned into meat pieces. Once a man sees separated legs, arms, butts, breasts and stomach, he is very likely to think of a woman as an object. These images which glorify women's sexual objectification can become perilous when it leads to violence towards women. There are also other images in which women are portrayed in restraints and some advertisements portray women as an inanimate object displaying products (fig. 4). These advertisements are the products of the trend that overlooks the fact that sexism and sexualizing violence against women is acutely adverse and ruinous. This trend normalizes violence against women by throwing these images into the popular culture of the west. Thereafter, cultural explanations can serve as beautiful justification for violence against women in the society. Culture is often "alleged to have a particularly influential explanatory power" in case of violence against women (Sokoloff \& Dupont, 2005, p. 45). This deliberate perpetuation of violence against women by advertisers has serious consequences in the west. A woman is beaten every nine seconds in the United States; about one-third of women killed each year in the United States are murdered by an intimate partner; a great number of women has been coerced into sex or has been abused during her lifetime in the west (Chemaly cited in Plank, 2013).
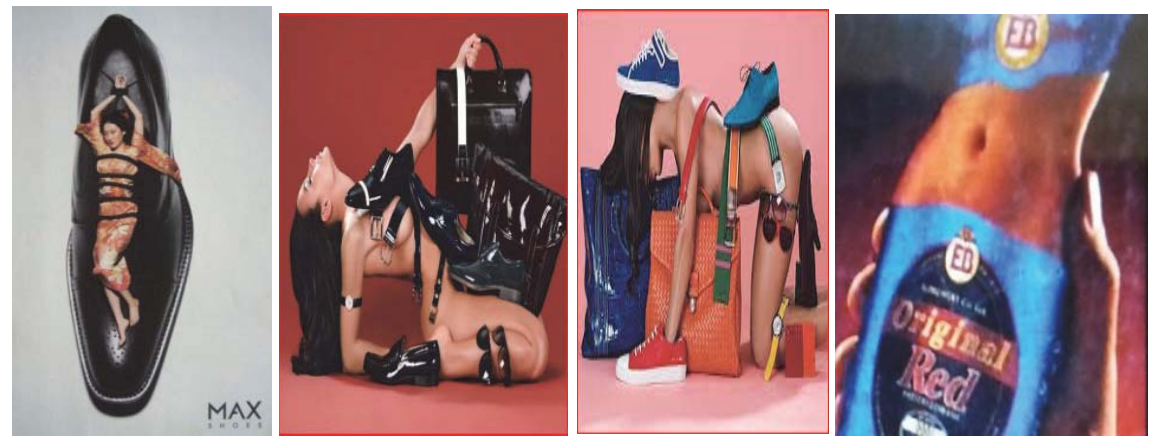

Fig.4. Advertisements depicting women as chained and inanimate objects 
Once women are represented as mannequins to display products, it reinforces the notion that women should be a taciturn being. It sends off the message that "shrinking back, being quieter, daintier" are more feminine (Michalides, 2005, p. 9). What is common in all these images of women in advertisements is beauty. Conventional beauty is the sole characteristic found in these advertisements. They are depicted as young, thin, tall with flat stomach and no lines of wrinkles, scars or blemishes (fig 5). These depictions in advertisements not only solicit and encourage the objectification of women but also make women feel they are not good-looking enough the way they are. Women are steadily encouraged to accomplish this ideal and feel ashamed if they fail. These beautiful women in advertisements represent the standard beauty which leads women to think that their lovability and desirability are banked upon their physical attraction. These advertisements tell women that they should try to look like the models and insinuate that they can be look like them if they buy the products. Advertisements that scream "no wrinkles," "less cellulite," "whiter and brighter smile" are all suggesting that the natural things that happen to a woman's body and face are not beautiful and to make it beautiful they should purchase the product to battle the ugliness (Michalides, 2005, p. 9). Many scholars of feminism argue that these narrowly framed images seriously affect the girls and women of a society as they create an uneasy gap for them comparing an idealized image and their own physical appearance (Silverstein et al., 1986). The impact is to the extent that even Kilbourne, the author and filmmaker studying the issue of women in adverting industry, feels the effect as she explains:

I've been studying these issues for decades and I still feel awful almost every time I read a fashion magazine. My belly is too round, my skin is marred by sunspots and wrinkles, my teeth not white enough, my nails not perfect. It's easy to write this off as trivial vanity, but the impact can be deep and serious. It makes it difficult for a woman to feel safe, at home in her body and, therefore, in the world (1999, pp. 258-259).
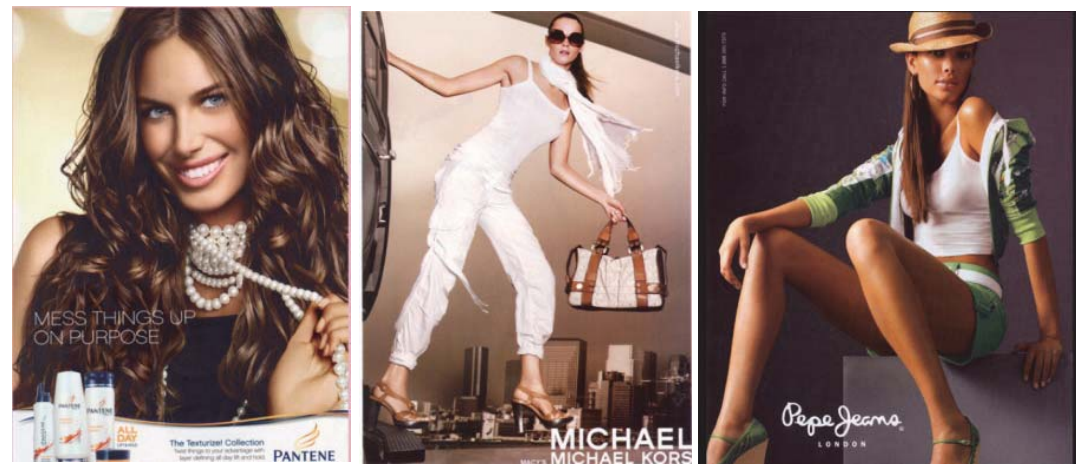

Fig.5. Advertisements depicting women as beautiful, thin and tall.

Persistently exhibiting thin women with impeccable beauty is a subtle form of symbolic annihilation as it is the distorted narrow perspective of female beauty. Seeing the same images of youth, thin, glowing skin and beauty leads people to have an infeasible idea of what a female should look like and puts physique at the forefront of a female mind (Shields, 2003). The repeated and frequent exposure to unrealistic beauty ideals through advertisements can render these images achievable and real. Page (2003) argues that vulnerability to these images can be found mostly in young girls as by the time they are 17, they are likely to have seen 250,000 advertisements many of which stress physical attractiveness and thinness as the standard of feminine beauty. Female consumers see these images and spend an incredible amount of money to buy products that will supposedly make them like the models in advertisements. For an average woman, it is almost next to impossible to live up to this ideal beauty and size without risky dieting and extreme exercise. Once failed to conform to the constructed ideal standard, they go to any great length of effort to "manipulate and change their faces and bodies" (Kuntjara, 2001, p. 99). As noted earlier, women to varying degrees develop self-objectification by internalizing the outsider view and comparing it with their own bodies (Fredrickson and Roberts, 1997). Unfortunately, what women do not know is that the women in advertisements are digitally rendered, heavily photoshoped and are the creation of artificiality which establishes an impossible standard of physical beauty (fig 6). 


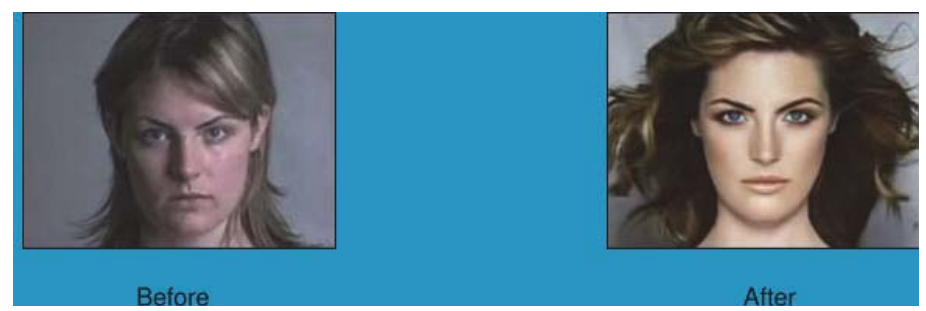

Fig.6. Face of a model before and after artificial creation. http://www.youtube.com/watch?v=Q-9tmCrEXdl

Emanated from these constructed images, body image dissatisfaction occurs. Body image is an individual's subjective attitude of how they think they look to other individuals (Bierma, 2003). It is, in fact, how people perceive themselves when they look in the mirror. The development of the body image is a lifetime process as people receive feedback about their bodies from other people which dramatically influence the formation of body images. There is only one way to define beauty in advertisements which includes one body type and one skin type. All the women can look like them by wearing the same clothes and using the same products the models use in advertisements. Negative body image is the direct result of self-objectification which happens through a social comparison process. Women constantly compare themselves with the models in the advertisements as they are represented as the societal norm and standard of feminine size and beauty. These images encourage women to strive for an unnatural and unhealthy body ideal which results in depression, low self-esteem and eating disorder. This sentiment is confirmed in a study by Fredrickson and Roberts (1997); they argue that self-objectification enhances women's concerns about physical attractiveness. They always have an apprehension of when and how their body will be looked at and assessed. They further argue that women reduce cognizance of internal body sensations such as stomach contractions, hunger and sexual arousal. They believe that selfobjectification also leads to an increase in women's anxiety about their physical safety which in turn cause depression, sexual dysfunction and eating disorder.

New wave feminism believes that there is nothing wrong with portraying a sexy woman in advertisement as they think a female sexuality is her power (Zimmerman \& Dahlberg, 2008). This trend of sexual objectification is increasingly spreading amongst the young women and they are likely to think of it as the norm and no longer harmful. Due to the dominance of sexuality in the media and the influence of the third wave feminism, young women appear to have no difficulty in accepting sexual objectification. What people in a society need to know is the fact that advertisements are abusing women by taking into account "not only the inherent qualities and attributes of the products they are trying to sell, but also the way in which they can make those properties mean something to us" (Williamson, 1978, p. 12). To make the products meaningful, advertisers utilize women and glamorize women's sexy bodies which promote the old stereotype of women as sex objects in a patriarchal society. Goffman $(1979$, p. 8) notes that gender representation in advertising industry reflects "fundamental features of the social structures" such as norms, beliefs and values. Awareness needs to be raised that the images in the advertisements are way different from the "real self" of a person in most cases (Williamson, 1978). There is no doubt that recently advertisements have started to portray women as strong, healthy and a professional but there are still far too many advertisements that glamorize violence against women and perpetuate the stereotypes.

Media literacy can mitigate the effect of the gendered advertisements (Anthony, 2009). It is a set of attitudes that people should constantly use to expose themselves to the media to decipher the messages they encounter (Potter, 2008, p. 19). It reveals to people that all the media messages are engineered to keep the appearance of a high level of reality but all of them are really one step removed from the reality. It helps people to recognize fantasy from the reality as they have a blurred vision of reality due to too much exposure to the images in the media (Potter, 2008). To be media literate, people should be aware of five core concepts: 1- "Principle of non-transparency" which suggest that media messages are all constructed, 2- "Codes and conventions" which indicates that to construct a message, media uses a creative language with its unique rules and regulations, 3- "Audience and decoding" which expresses that media messages are interpreted differently, 4- "Content and message" shows that there are embedded values and points of view in media and 5"Motivation" which is suggestive of the fact that gaining power and profitability are media's objectives (Center for Media Literacy 2009 cited in Anthony, 2009, p. 17). Knowing these concepts empowers the audience to develop a critical look and challenge the myths of the stereotypes of women. 


\section{Conclusion}

Drenched in a visual environment, people are awashed and bombarded by images of young, beautiful, thin, tall and sexy women. The women are selected and pictured to sell products, attract attention and please male viewers. The difference between the way men and women are depicted in advertisements are stark. Too often, the chosen women are depicted stereotypically as weak, domesticated and dependent on men. They are not presented as a whole person; instead they are reduced to the sum of their body parts. Despite many feminist scholars' criticism, since the 1970s, against denigrating and objectifying women, sexual objectification of women still continues, their subordination ritualized and their sexuality glamorized. These images continue to shape and influence people's attitude in viewing gender. The gendered advertisements beget desensitization of violence against women and they cause many women to develop selfobjectification. As the fair sex of the society, women are made to believe that the women in the advertisements are the standard and ideal beauty. They try hard to achieve the constructed beauty by purchasing the products unaware of the fact that the images in the advertisements are the creation of artificial construction. Thus, these images leave a dramatic impact upon the formation of attitudes towards gender. What people need is media literacy to help them distinguish fantasy from reality. This literacy will inform them that advertisers utilize particular techniques to create "reality" from the constructed and unrealistic images.

\section{References}

Anthony, M. C. (2009). Images of girls and women in the media: A media literacy project to mitigate the influence of beauty product advertising for girl scouts. Master thesis. Gonzaga University.

Bardwick, J., \& Schumann, S. (1967). Portrait of American men and women in TV commercials. Psychology 4 (4), pp. 18-23.

Bessenoff, Gayle R. (2006). Can the media affect us: Social comparison, self-discrepancy, and the thin ideal. Psychology of Women Quarterly 30 (3), pp. 239-251.

Bierma, P. (2003). Body image. Principle Health News. Retrieved from http://www.principalhealthnews.com/topic/bodyimage ;jsessionid=VUJPSIZZOY QSCTY

Byerly, C.M. \& Ross, K. (2006). Women \& media: A critical introduction. Malden, MA: Blackwell Publishing.

Caputi, J. (1999). Pornography of everyday life, in Marian Myers (ed.), Mediated Women: Representations in Popular Culture. Cresskill, NJ: Hampton Press, pp. 57-80.

Culler, J. (1981). The pursuit of signs: Semiotics, literature, deconstruction. London: Routledge \& Kegan Paul.

Davis, D. M.(1990). Portrayals of women in prune-tune network television: Some demographic characteristics. Sex Roles, 23 (32).

Duke, L.L., \& Kreshel, P.J. (1998). Negotiating femininity: Girls in early adolescence read teen magazines. Journal of Communication Inquiry 22, pp. 48-71.

Felski, Rita. (2000). Doing Time: Feminist Theory and Postmodern Culture. New York and London: New York University Press.

Fisher, B., Cullen, F., \& Turner, M. (2000). The sexual victimization of college women. Washington, DC: U.S. Department of Justice, National Institute of Justice, and Bureau of Justice Statistics.

Frederickson, B.L., \& Roberts, T.A. (1997). Objectification theory: Toward understanding women's lived experiences and mental health risks. Psychology of Women Quarterly 21, pp. 173-206.

Gallagher, Margaret. (1979). The portrayal and participation of women in the media. Paris: United Nations Educational, Scientific and Cultural Organization (UNESCO).

Geis, F.L., Brown, V., Jennings, J., \& Porter, N. (1984). TV commercials as achievement scripts for women. Sex Roles 10 (7, 8), pp. 513-525.

Gerbner, G., Gross, L., Morgan, M., \& Signorielli, N. (1980). The mainstreaming of America: Violence profile no. 11. Journal of Communication 30(3), pp. 10-29.

Goffman, E. (1979). Gender advertisements. New York: Harper/Colophon.

Gough-Yates, Anna. (2003). Understanding Women's Magazines: Publishing, Markets and Readerships. London: Routledge.

Karl, Herb. (1994). The image is not the thing, in Roy F. Fox (ed.) Images in language, media and mind. Urbana, Illinois: National Council of Teachers of English. pp.193-203.

Kang, M.- E. (1997). The portrayal of women's images in magazine advertisements: Goffman's gender analysis revisited. Sex Roles 37, pp. $979-997$.

Kilbourne, Jean. (1999). Beauty ... and the beast of advertising, in Diana George \& John Trimbur (ed). Reading culture .New York: Addison Wesley Longman, Inc. pp. 178-184.

Kilbourne, Jean. (2000). Killing us softly 3 : advertisings' effects on women.

Kuntjara, H. Esther. (2001). Beauty and the Beast: Images of Women in Advertisements. NIRMANA 3 (2), pp. 97 - 106.

Linder, Katharina. (2004). Images of Women in General Interest and Fashion Magazine Advertisements from 1955 to 2002 . Sex Roles $51(7 / 8)$.

McArthur, L.Z., \& Resko, B.G. (1975). The portrayal of men and women in American television commercials. The Journal of Social Psychology 97, pp. 209-220. 
Michaelides, A. (2005). Hidden messages: Advertising and the messages they send to society about women. Senior honor theses. Eastern Michigan University.

Mulvey, Laura. (1979). Feminism, Film and the Avant-garde, in Jacobus, Mary (ed.),Women Writing and Writing about Women. London: Croom Helm, pp. 177-95.

Page, T.S., (2003). Fostering emotional well-being in the classroom. Boston: Jones \& Bartlett.

Pierson, Ruth Roach. (1986). They're Still Women After All: The Second World War and Canadian Womanhood. Toronto: McClelland and Stewart.

Plank, Elizabeth. (2013). Dear Advertisers, There's nothing sexy about violence against women. Available from http://www.policymic.com/articles/74785/dear-advertisers-there-s-nothing-sexy-about-violence-against-women

Potter, W.J. (2008). Media literacy. California: Sage Publications.

Pritchard, A. (2001). Tourism and representation: A scale for measuring gendered portrayals. Leisure Studies 20, pp. 79-94.

Reichert, Tom, et al. (2007). A Test of Media Literacy Effects and Sexual Objectification in Advertising. Journal of Current Issues \& Research in Advertising 29, pp. 81-92.

Silverstein, B., Perude, L., Peterson, B., \& Kelly. (1986). The role of the mass media in promoting a thin standard of bodilv attractiveness for women. Sex Roles, 5 (14), pp. 519-532.

Shields, Vicki. (2003). Measuring up, how advertising affects self-image. NWSA Journal 15.

Sokoloff, N. J., \& Dupont, I. (2005). Domestic violence at the intersections of race, class, and gender: Challenges and contributions to understanding violence against marginalized women in diverse communities. Violence Against Women, 11, pp.38-64.

Spencer, Stephan. (2011). Visual research Methods in the Social Sciences: Awakening Visions. Routledge, New York.

Stankiewicz, Julie, and Francine Rosselli. (2008). Women as Sex Objects and Victims in Print Advertisements. Sex Roles 58 (7/8), pp. 579-589.

Tuchman, Gaye. (1978). Introduction: the symbolic annihilation of women by the mass media, in Gaye Tuchman, Arlene Kaplan Daniels, and James Benet (eds.) Hearth and Home: Images of Women in the Mass Media. New York: Oxford University Press.

Van Zoonen, Liesbet A. (1995). Gender, Representation, and the Media, in John Downing, Ali Mohammadi, Annabelle SrebernyMohammadi (eds.) Questioning the Media: A Critical Introduction. Thousand Oaks, Calif.: Sage, 1995. 311-328.

Wells, W; Burnett, J \& Moriarty , S. (1997). Advertising: Principles and Practice. Prentice Hall College Div.

White, J. W., Donat, P. L. N., \& Bondurant, B. (2001). A developmental examination of violence against girls and women. In R. K. Unger (ed.), Handbook of the psychology of women and gender. New York, NY: Wiley. pp. 343-357.

Williamson, J. (1978). Decoding Advertisements. London: Marion Boyars.

Wolska, M. (2011). Gender stereotypes in mass media. Case study: Analysis of the gendered stereotyping phenomenon in commercials. Available from http://krytyka.org/gender-stereotypes-in-mass-media-case-study-analysis-of-the-gender-stereotyping-phenomenon -in-tv-commercials/

Wood, T, Julia. (1994). Gendered Media: The Influence of Media on Views of Gender, in Gendered Lives: Communication, Gender, and Culture by Julie T. Wood, Chapter 9, pp. 231-244.

Zimmerman, A, Dahlberg. J. (2008). The Sexual Objectification of Women in Advertising: A Contemporary Cultural Perspective. Journal of Advertising Research. March 2008. 